\title{
¿Cómo acompañar el discernimiento vocacional de jóvenes en el contexto posmoderno?"
}

\author{
Edgar Javier Ruiz Mora, SDB ${ }^{* *}$ \\ Hernán Cardona Ramírez, sDB ${ }^{* * *}$
}

Recepción: 10 de julio de 2018 • Aprobación: 5 de agosto de 2018

\section{Resumen}

El acompañamiento espiritual vocacional es una necesidad apremiante en el camino de vida de todo bautizado. Este ha de servirle como instrumento para discernir las circunstancias de la vida, a todo aquel que anhela en lo más profundo de su corazón hacer la voluntad de Dios. Para alcanzar este fin, los jóvenes deben ser educados y acompañados en la práctica de sus ejercicios espirituales, de tal manera que puedan reconocer el modo como acontece Dios en la propia vida y en la vida de la comunidad eclesial en el contexto posmoderno.

Palabras clave: acompañamiento espiritual, voluntad de Dios, ejercicios espirituales, posmodernidad, discernimiento vocacional.

* Artículo de investigación. Citar como: Ruiz, E. y Cardona, H. (2020). ¿Cómo acompañar el discernimiento vocacional de jóvenes en el contexto posmoderno? Albertus Magnus, XI(1), 125-147. https://doi.org/10.15332/25005413/6192

** Universidad Pontificia Bolivariana, Medellín, Colombia. orcid: https://orcid.org/00000002-6713-202X. Correo electrónico: javieruizsdb@gmail.com

*** Pontificia Universidad Javeriana, Bogotá, Colombia. oRCid: https://orcid.org/0000-00034290-3075. Correo electrónico: hcardona@une.net.co 


\title{
How to accompany the vocational discernment of young people in the postmodern context?
}

\begin{abstract}
Vocational spiritual accompaniment is a pressing necessity in the life path of every baptized person. This must serve as an instrument for discerning the circumstances of life for all those who yearn in the depths of their hearts to do the will of God. To achieve this end, young people must be educated and accompanied in the practice of their spiritual exercises, in such a way that they can recognize the way God happens in their own life and in the life of the ecclesial community in the postmodern context.

Keywords: spiritual accompaniment; will of God; spiritual exercises; postmodernity; vocational discernment.
\end{abstract}

\section{Como acompanhar o discernimento vocacional dos jovens no contexto pós-moderno?}

\section{Resumo}

O acompanhamento espiritual vocacional é uma necessidade premente no caminho de vida de cada batizado. Deve servir de instrumento para discernir as circunstâncias da vida, para quem deseja do fundo do coração fazer a vontade de Deus. Para tanto, os jovens devem ser educados e acompanhados na prática de seus exercícios espirituais, de forma que possam reconhecer o modo como Deus acontece em sua própria vida e na vida da comunidade eclesial no contexto pós-moderno.

Palavras-chave: acompanhamento espiritual; vontade de Deus; exercícios espirituais; pós-modernidade; discernimento vocacional. 


\section{Introducción}

El presente artículo tiene por objeto profundizar en la esencia del acompañamiento vocacional, desde la práctica de los ejercicios espirituales como camino pedagógico y posibilitador de discernimiento cristiano a jóvenes de noveno, décimo y undécimo grado, en el proceso de discernimiento vocacional, tomando como referencia algunos textos básicos ofrecidos por la reflexión teológica y la enseñanza cristiana, que permitan una disertación seria y profunda en este campo espiritual teológico.

Para encontrar la respuesta a cómo acompañar el discernimiento vocacional de jóvenes en el contexto posmoderno, se debe partir de la convicción de que todo ser humano está llamado a la comunicación con Dios, en quien descubre su dignidad y fundamento. Él tiene un plan de salvación para cada persona, y esta, a su vez, como "Oyente de la Palabra" (Rahner, 1976), debe discernir los signos históricos para responder al don vocacional revelado, lo cual le supone un camino vinculante con la divinidad. Solo Dios da respuesta plena y total al problema del ser humano, es Él quien da sentido a la vida y responde los anhelos más profundos del corazón. Así, al asumir lo anterior se podrán abordar con fundamento tres escenarios de disertación que buscan por sí mismos desarrollar el objeto del presente ejercicio: 1) ver en qué realidades existenciales necesitan ser acompañados los jóvenes posmodernos; 2) juzgar cómo discierne el ser humano la Voluntad de Dios; y 3) establecer cuál es la esencia de los ejercicios espirituales. Para que, finalmente, se pueda proponer un camino pastoral de acompañamiento espiritual desde el discernimiento vocacional en los ejercicios espirituales para los jóvenes de hoy.

\section{El desafío de ser cristiano en la cultura posmoderna: ¿en qué realidades existenciales necesitan ser acompañados los jóvenes posmodernos?}

La modernidad aparece en la historia de la humanidad como una propuesta sociocultural diferenciadora de la concepción teocéntrica propia del Medioevo. El sujeto es, en la Era Moderna, el centro del universo y entorno a él se configura una novedosa comprensión del ser humano y de su manera de relacionarse con el mundo, se da, entonces, una "reivindicación frente a la naturaleza, y sus efectos esclavizadores, por la ciencia y la tecnología. La autonomía del hombre 
con relación al fideísmo, por medio de la razón; y la independencia frente a los poderes absolutistas y represivos" (Ruiz, 2015, p. 22), son indicadores claros del nuevo giro que vive la humanidad, sin embargo, la promesa de emancipación y dignificación del sujeto prometidos en la modernidad, son incapaces de dar respuesta a los anhelos más profundos del ser humano. Desde este contexto, la posmodernidad ${ }^{1}$ se presenta como nueva manera de ver y de disfrutar la vida frente a los problemas no resueltos por la cultura moderna:

La posmodernidad se caracteriza por: (a). la permanencia irreversible de la crisis de valores, es decir, de la secularización, (b). La pluralidad de los lenguajes correspondientes a los distintos discursos valorativos; (c). La secularización del progreso, en el aspecto de que las sociedades han perdido el sentido de su destino, y el devenir no tiene finalidad. El futuro ha muerto y todo es ya presente; $y$ (d) el cambio de las coordenadas espacio-temporales. (Giner et al., 1998, p. 591)

Tres características definen la posmodernidad: "pluralismo, diferencia y fragmentación" (Roldán, 2004, p. 5), las cuales ponen en jaque la experiencia de fe cristiana hoy y afectan de manera relevante la posibilidad de hacer opciones cristianas maduras, en consecuencia, frente a estas trasformaciones, surge el interrogante: ¿cómo ser cristiano hoy?, que se formula la Iglesia ante un contexto plural y diverso que desborda la experiencia eclesial y le exige una postura frente al creciente desafío pastoral de vivir la fe en el mundo posmoderno. Tertuliano, en el siglo II de la era cristiana, afirmó: "Hácense, no se nacen los cristianos" (Tertuliano, 1789, p. 85), lo que nos hace pensar en la esencia cristiana como experiencia dinámica procesual que parte del encuentro con el Señor y exige una respuesta radical de fe. "No se comienza a ser cristiano por una decisión ética o una gran idea, sino por el encuentro con un acontecimiento, con una Persona, que da un nuevo horizonte a la vida y, con ello, una orientación decisiva" (Benedicto XVI, 2006, p. 1). Cada persona es sujeto, es capaz de decidir entre las diferentes

1 "Es un cambio cultural radical o incluso una nueva época, después de la época de la Modernidad - determinada como estaba, o todavía lo está, por el racionalismo, la creencia en el progreso y la tecnocracia - , que ha entrado en una profunda crisis [...] o que ha llegado a su fin. [...] Se caracteriza por el rechazo del pensamiento absolutista y totalitario de los modelos directivos válidos para todos basados en las pretensiones hegemónicas y en los monopolios que han de sustituirse por la afirmación de la diferencia y la pluralidad en todos los sectores, y la variedad de concepciones del mundo, orientaciones, formas de pensar verdes, formas de saber, sistemas de valores, "mundos culturales", los de lenguaje, tendencias culturales, estilos de vida y pautas de conducta" (Heinz, 2005, p. 717). 
opciones que se le presentan en la vida, por esto, "la dificultad de ser cristiano en nuestros días no está en la persona de Jesús, como en el orden disciplinar o moral" (Raczkiewicz, 2010, p. 28). La "Gaudium et Spes" exhorta como deber cristiano "escrutar a fondo los signos de los tiempos e interpretarlos a la luz del Evangelio" (GS, n. 1), como exigencia fundamental de vida cristiana para responder a los desafíos que se le presentan al cristiano hoy.

El panorama descrito evidencia la urgente necesidad de discernir lo verdaderamente auténtico. Aquello que da sentido a la existencia, es motivo de lucha y razón de vivir, por ello “quien procura la vida busca a como dé lugar lo auténtico. Si en el mundo actual es plausible el pensamiento sobre la vida, vale la pena resolver el sentido de la vida" (Frankl, 2003, p. 33), en consecuencia, "lo auténtico procura una vida plena, espiritual y trascendente. El ser humano por definición desde la filosofía de la religión, es capaz de Dios como un hecho antropológico, es decir esencial a la naturaleza humana" (Torralba, 1998, p. 125). Se despierta una necesidad imperiosa de buscar nuevos caminos en el devenir de la cultura posmoderna, la cual pareciera no encontrar fondo en una filosofía del 'todo vale', todo se puede y todo da lo mismo; por lo que es apremiante discernir sobre la propia vida y el sentido de la misma ¿para qué vivir?, ¿cómo vivir?, ¿por qué vivir?, cuestionamientos que resumen la historia de la humanidad como una búsqueda por encontrar, o tal vez, dar orientación a la existencia misma, pues ¿tiene la vida humana un sentido y el hombre un destino? (Blondel, 1993, p. 3).

¿Qué puedo saber?, ¿qué debo hacer?, ¿qué me cabe esperar?, ¿qué es el hombre? (Kant, 2003, p. 13). Aún no se hallan respuestas plenas, son interrogantes tan antiguos como nuevos que ni la ciencia ni la cultura posmoderna han podido responder, y que también cuestionan a los jóvenes de esta época. Ante esta realidad,

[...] las circunstancias nos invitan a prestar una atención especialísima a los jóvenes. Su importancia numérica y su presencia creciente en la sociedad, los problemas que se les plantean deben despertar en nosotros el deseo de ofrecerles con celo e inteligencia el ideal que deben conocer y vivir. (Pablo VI, 1975, p. 32)

Por lo mismo, se debe acompañar al joven a encontrar respuestas en el discernimiento de su vocación cristiana y su papel en medio del mundo en el que nos ha correspondido ser cristianos; si se quiere vivir con autenticidad los valores del Evangelio siendo fermento en medio del mundo, se debe estar atento a la 
escucha de la Palabra y los acontecimientos de la historia a través de los cuales Dios llama y convoca.

\section{Naturaleza y fundamento del acompañamiento espiritual en el proceso de discernimiento vocacional}

El acompañamiento espiritual es, quizás, una de las prácticas pastorales eclesiales menos ejercitada por los creyentes, pues vivimos inmersos en una sociedad que poco considera necesaria la ayuda o el acompañamiento de los demás. Sin embargo, lo primero a tener en cuenta en el camino de la vida espiritual es que no se discierne solo, sino de la mano de un acompañante espiritual. Por lo tanto, "necesitamos ejercitarnos en el arte de escuchar, que es más que oír. Lo primero en la comunicación con el otro, es la capacidad del corazón que hace posible la proximidad, sin la cual no existe un verdadero encuentro espiritual" (Francisco, 2013, p. 162).

Antes de adentrarnos en el sentido propio del acompañamiento espiritual, optamos por el uso del término acompañamiento en vez de dirección espiritual, por cuanto el primero ofrece una óptica de mayor cercanía y confianza entre quien acompaña y quien es acompañado, mientras el segundo presenta una connotación más directiva y menos sugerente de libertad; sin embargo, se debe precisar, con respecto al objeto perseguido, que ambos términos se entienden como equiparables.

\footnotetext{
"Dirección espiritual" es el nombre clásico desde sus orígenes. [...]. Llevada a cabo principalmente por el "padre" o el "maestro", estableciendo una distancia grande con respecto al "hijo" o al "discípulo". En cambio, "acompañamiento" sugiere una relación más fraterna, donde quien ayuda es un "hermano/a mayor" de la persona acompañada, reduciéndose también la intensidad de la directividad. (Cebollada, 2017, p. 295)
}

La opción por el término acompañamiento, pretende ofrecer un vocabulario más diciente al contexto actual, en el cual se denota una alta sensibilidad por principios y valores que reivindiquen la autonomía y libertad propias del ser humano, en ocasiones violentadas u opacadas por escenarios religiosos o moralistas 
con carácter controlador, que poco espacio ofrecen a la autorrealización y afirmación de la propia existencia.

Solo se puede acompañar caminando al lado de, pero nunca, recorrer el camino, tomar una decisión y menos ser feliz por otro. El acompañamiento, en últimas, es compartir con otro la existencia, hacerse compañero que anima, ayuda y apoya, pero nunca sustituye ni reemplaza.

A quienes atañe de cualquier manera la formación de los niños y de los jóvenes, edúquenlos de forma que, conociendo la solicitud del Señor por su rebaño y considerando las necesidades de la Iglesia, estén preparados a responder generosamente con el profeta al Señor, si los llama "Heme aquí envíame". [....] Para conseguir esto es muy importante la diligente y prudente dirección espiritual. (PO, n. 11)

Sin embargo, reconocer la manera como actúa Dios no es fácil para nadie, ni tampoco lo es acompañar al joven en este reconocimiento, pues los tiempos, y las maneras como el Señor procede, no coinciden con los afanes propios del ser humano, quien no pocas veces desea que las cosas acontezcan según su propia voluntad. Descubrir el modo como acontece Dios en la historia, requiere un camino de formación en la vida espiritual a través de la oración, el acompañamiento y el discernimiento, que disponga y prepare para acoger las mociones del espíritu en la historia personal y comunitaria de vida de los creyentes.

La Voluntad Divina se desarrolla en un tiempo determinado, para una persona o comunidad concreta y tiene una finalidad propia, manifestada mediante el acontecimiento revelado. En este sentido, son presupuestos necesarios para hablar de acompañamiento espiritual en cualquier caso o circunstancia, las siguientes condiciones: 1) conocer al acompañado y llegar al fondo de su corazón. Pues ello ha de considerarse el punto de partida sin el cual sería imposible pensar en un fructífero acompañamiento. No se puede ser compañero de camino tomando como eje referencial ideales, doctrinas, o normas prestablecidas por la moral, la religión, o los pareceres de otros; cuanto más se valora la identidad de quien es acompañado, lo que piensa, siente y hace, más acertada será la dirección hacia dónde se orienta el corazón; 2) no se parte de sueños fabricados sino de realidades constatadas en la propia experiencia de vida. Por ello, es necesario generar un clima de confianza y apertura que ayude a acrecentar la relación de amistad o configuración con el Señor, pues este, y no otro, ha de ser el propósito mismo de acompañar en la vida de fe a una persona. En dónde se está y hacia dónde se va 
en el horizonte relacional con Dios, son los objetos del discernimiento, el cual posibilita la relación madura, profunda y empática entre el acompañante y el acompañado; y 3) el discernimiento al cual se llega como fruto del conocimiento propio y la relación de amistad con el Señor. Pues no basta con conocerse a sí mismo, se debe poner en mutua relación lo que se es, con lo que el Señor espera de la persona, en otras palabras, se hace necesario integrar las características propias de la identidad con la misión del ser humano, mediante el ejercicio del discernimiento espiritual profundo.

En pocas palabras, sin "el conocimiento propio del acompañado, su relación personal con Dios y el discernimiento en acompañante y acompañado", no hay acompañamiento espiritual" (Cebollada, 2010, p. 296), por lo que pueden variar las formas y estilos, pero no estos elementos fundamentales. Ellos son el eje referencial de un auténtico proceso de acompañamiento espiritual, en el cual no puede faltar el protagonismo del Espíritu Santo, verdadero maestro de vida espiritual, quien suscita, anima y conduce de manera segura a quienes bajo esta práctica espiritual meditan y acogen con actitud profunda de fe los signos de la voluntad de Dios en las situaciones concretas de la vida.

Ante los presupuestos anteriormente expuestos surgen interrogantes como: ¿qué se entiende por acompañamiento espiritual? y ¿cuál es la finalidad del mismo?

Acompañar "consiste en ayudar a las personas en su proceso de crecimiento en la fe y en orden a clarificar y discernir la voluntad de Dios, y llegar a un compromiso y opción vocacional mediante la Palabra de Dios, los sacramentos y la oración. Habrá que cuidar el compromiso apostólico, la escucha, el diálogo, el testimonio y otras muchas claves, respetando el desarrollo de cada persona que camina hacia la configuración con Cristo". (García, 2001, p. 21)

El Espíritu Santo, como se ha dicho, es el guía que acompaña y mueve los corazones para abrirse a Dios, por lo que la persona que orienta este camino debe comprender su función de ayudar a descubrir cómo actúa la gracia de Dios en la historia personal de cada uno, y cómo se puede responder a su proyecto de salvación, por cuanto no se puede sustituir al acompañado en su camino de respuesta a Dios. Ante todo, es necesario respetar el libre albedrio, sin pretensiones directivas o coercitivas indicadoras de aquello que está bien o mal, lo que se debe hacer o evitar. "La verdadera 'dirección espiritual' tiene como fin iluminar, alentar, orientar, estimular, ayudar a discernir y hacer crecer humana y espiritualmente 
a la persona, mediante un acompañamiento cercano y personal" (Severino, 1997, p. 125).

Hablar de la acción de Dios en la propia vida tiene como punto de partida la realidad misma de cada uno, Dios se encarnó para mostrarnos que la santidad de vida es posible en tanto más se asuma la propia humanidad; en Cristo el ser humano halla su plenitud de vida y el grado más alto de perfección, en este sentido, "la vida de Dios se manifiesta en la vida humana, aun contando con su pequeñez y limitación, y, por lo tanto, fuera de esta humanidad que nos es propia, es imposible comprender y experimentar la salvación" (Lasso, 2011, p. 17).

El objetivo primero del acompañamiento espiritual es ayudarnos a descubrir quiénes somos y de qué manera realizamos nuestra humanidad a la luz del proyecto de salvación. El acompañamiento no pretende ayudar a discernir los fines (la santidad de vida en este caso) sino los medios como se alcanzan los primeros.

No se puede pretender estandarizar la práctica del acompañamiento, y menos en orden al discernimiento vocacional, pero es irrefutable que la espiritualidad cristiana contemporánea tiene tres características las cuales no se pueden obviar en el proceso de discernimiento espiritual y se presentan de capital importancia para la plenificación de lo humano a la luz de la revelación divina:

(a) Una espiritualidad de lo cotidiano (en clave de inserción y no de huida de la realidad, superando la evasión y el dualismo), (b) una espiritualidad que busca la autorrealización en la autotrascendencia (apertura al Otro en los otros, para no caer en el subjetivismo narcisista), y (c) una espiritualidad capaz de integrar la contemplación en la acción (evitando los extremos del activismo y del intimismo). (Mifsud, 2002)

El ejercicio del acompañamiento permite ayudar a descubrir en qué medida se está viviendo la opción fundamental y de qué manera ese proyecto particular de vida tiene consonancia con la implantación del Reino en la propia existencia y en el proceso de seguimiento de la persona del Señor Jesús. Por tanto, la vivencia de los ejercicios espirituales, propuestos como instrumento de ayuda espiritual en la vida de fe, posibilita discernir la llamada en un ambiente de fe, confianza, libertad y gracia de Dios, no sin un adecuado proceso de acompañamiento espiritual.

“El acompañamiento parte de las cuestiones que plantee cada persona acompañada, pero busca un objetivo principal: ayudar a la persona acompañada a ser más fiel a su condición cristiana, a seguir a Cristo e imitarle, a configurarse con 
Él según su propia vocación" (García, 2017, p. 874) Ese es el camino que se ha de proponer, seguir y evaluar desde la práctica de los ejercicios espirituales, con el fin de llevar a efecto un proceso serio, maduro y profundo de vida cristiana hoy; tarea nada fácil considerando el contexto en el cual se desenvuelve la presente propuesta, pues está enmarcada por una vivencia cómoda y tradicionalista de la fe, masificada por una experiencia religiosa que ha reducido el Evangelio a escenarios de aprobación sociocultural.

"La vida cristiana es 'camino' es vivir del Espíritu (Ga 5, 25), como sintonía, relación, imitación y configuración con Cristo, para participar de su filiación divina" (Congregación para el Clero, 2011, p. 57), este camino se construye al andar, y demanda una renuncia a los valores y propuestas del mundo que no coinciden con el Espíritu evangélico propuesto por Jesús. De esta manera, lo primero del acompañamiento espiritual será poner en sintonía la propia vida, de cara al proyecto cristiano de humanización.

El objetivo de la vida cristiana está en ser uno con Cristo como él lo es con el Padre y el espíritu, a través de la experiencia de la filiación y en la comunión de vida con los demás: la Fraternidad. Solo desde este escenario es posible alcanzar la santidad, la comunión de vida con Dios y con los hermanos. Alcanzar este objetivo exige responder ¿cómo percibe el ser humano la voluntad de Dios?, en otras palabras ¿cómo opera Dios?, ¿cómo habita en el ser humano? Es decir, cualquier palabra o actitud de Jesús es incomprensible cuando no se ha tenido experiencia personal de Dios. Si no se sabe cómo actúa Dios en la historia y se aprende a descubrir allí su compañía, los ejercicios espirituales no sirven de nada, son infecundos, resultan vacíos.

Los ejercicios espirituales le permiten al ejercitante, como primer logro, una apertura constante a Dios como lo hizo Jesús. Es llegar al grado de consciencia de reconocer a Dios existiendo en el ser humano concreto, "como lo recuerda Karl Rahner: 'cuando Dios crea al ser humano, no crea una cosa como quien pone otro distinto de él mismo', [...] esto quiere decir que esta existencia es el acontecer de Dios mismo" (Baena, 2003, p. 39). La tarea del ser humano no es otra distinta a la de ejecutar, realizar su existencia y desde allí interpretar la acción de Dios en cada persona. No como una marioneta movida por otro, pues el sentido de la libertad no se detiene en lo que Dios hace conmigo, sino en lo que yo le permito hacer. La esencia de Dios es salir de sí y habitar en el otro, en este sentido, la esencia del ser humano se hace plena en el ejercicio de la libertad que lo pone en salida, cuando se está en función del otro, de esta manera, "la revelación es pues, la historia del acompañamiento espiritual (del Espíritu mismo) a la criatura, (al hombre y al 
mundo), hasta que acontezca plenamente la voluntad salvífica de Dios" (Franco, 2004, p. 11), es la historia de cómo el pueblo elegido por Dios descubre su compañía en el proceso de liberación y cómo cuida de él hasta llevarlo a la tierra prometida; de manera especial cada vocación profética lleva consigo un anuncio, un proceso de escucha, acompañamiento y liberación, no solo personal sino de toda una comunidad. Sin embargo, es nuestro interés acercarnos más al modo como Jesús Maestro de vida acompaña a sus discípulos.

\section{3. ¿Qué son y cuál es la finalidad de los ejercicios espirituales?}

Se pueden constatar al menos dos momentos importantes de los ejercicios espirituales dentro de la experiencia cristiana: en primer lugar, los ejercicios que tenían por finalidad la ejercitación del alma, que, a través de la lucha ascética, en el sentido clásico del término, buscaban el dominio de las pasiones para ponerse al servicio exclusivo de Dios, alejándose del mundo y de todo aquello que les distrajera de su objeto final. En segundo lugar, los ejercicios espirituales que tienen por objeto la meditación de la vida de Cristo y los valores del Evangelio, buscando así los caminos de perfección, propios del corazón ejercitante que anhela hacer la voluntad divina según la elección del propio estado de vida, como insistiría san Ignacio de Loyola en la vivencia de los ejercicios espirituales por él propuestos. A este respecto, según Melloni:

La práctica de los "ejercicios espirituales" es antigua en la Iglesia. De algún modo, aparece ya con Orígenes y Evagrio Póntico, que hablan de la vía activa, refiriéndose al ejercicio del dominio de las pasiones. Lo retorna Casiano bajo la expresión exercitia virtutum. A partir del s. XII empieza a utilizarse con frecuencia la expresión "exercitia spiritualia". Con la devotio Moderna los ejercicios espirituales se mencionarán y practicarán con profusión. Por otro lado, la costumbre de retirarse un tiempo a dedicarse a la vida de oración y penitencia existe desde los primeros siglos del cristianismo. [...] Los "ejercicios espirituales", como expresión contiene en sí los dos elementos de la vida cristiana: su aspecto ascético - askésis significa literalmente en griego "ejercicio" - y su aspecto místico - espiritual, pnematikós, es decir, procedente del Espíritu Santo-. Desde San Pablo, lo espiritual se distingue no de lo corporal, sino de lo psíquico (cf. I Cor 2,12-15). Lo espiritual es lo que está abierto a la acción 
del Espíritu, es decir, lo que no procede de uno mismo, sino que es recibido.

(Melloni, 1998, p. 12)

La vida monástica y cenobítica de los primeros siglos del cristianismo expresó los ejercicios 'espirituales' (sin tener aún este calificativo) en tónica de vigilancia del corazón, para no ceder al pecado y a las seducciones del mal, dedicando algunos días a la vida de piedad, oración y lectura espiritual como medios que permiten el dominio del cuerpo y sus pasiones, así como la íntima unión con Dios.

Después de este primer momento histórico de los ejercicios espirituales a nivel general, se va haciendo más común la práctica de los mismos, con una tonalidad de carácter cristocéntrico, cuyo punto de partida está en la meditación de la vida de cristo 'especialmente su pasión' y los valores evangélicos, los cuales permiten ir descubriendo en la vida del ejercitante la voluntad de Dios y, por ende, la manera de servir más y mejor al Creador. En consecuencia, para san Ignacio, la centralidad de los ejercicios se encuentra en: "poder en todo amar y servir a la Divina Majestad, de suerte que la gran tarea del ejercitante es el vencimiento propio, para ir quitando todas las afecciones desordenadas" (Oraá, 1954, p. 837).

La ejercitación espiritual es un camino que exige el esfuerzo de la voluntad humana y la efusión de la gracia divina, para poder descubrir la paz y la felicidad interior, no sin antes pasar por un camino de docilidad a la acción misma del Espíritu Santo, auténtico maestro de vida espiritual y de discernimiento cristiano a la luz del querer divino, pues es en el corazón mismo de la vida donde se halla a Dios, en lo gratificante y difícil de la existencia humana, en los avatares da cada día, en las personas y en las circunstancias del humano trasegar. En consecuencia, la vida cristiana la define, por su centralidad en el mandamiento del amor, en una doble dirección: el amor a Dios (filiación) y el amor al prójimo (fraternidad), que se convierten en la expresión más clara, viva y fundamental del discipulado, el cual necesita de un acompañamiento para responder al querer divino constatado mediante la práctica de los ejercicios espirituales. Es así como

la vida cristiana es más que una teoría, una moral o un compromiso y mucho más que una organización: es una pasión ardiente [...] Dejarse "abrazar por el amor de Dios" y aprender a convertir toda la vida en "amor y servicio". (De Loyola, 1983, p. 138) 
De esta manera, el peregrino - en su acepción más genérica- necesita de otros que lo acompañen y ayuden en su caminar; de igual manera, ninguno se convierte, ni mucho menos se hace cristiano, de la noche a la mañana. Es necesario el acompañamiento para hacer camino; pero para ser discípulo se requiere de un maestro.

Los ejercicios espirituales se hacen necesarios en la vida cristiana, por cuanto el cristiano vive en una sociedad y cultura determinadas, con principios y valores propios que, quizás, no corresponden a los valores característicos de la experiencia cristiana, por ello, son necesarios los espacios de encuentro y discernimiento de la Voluntad de Dios para mantenerse firmes en el camino elegido desde la gracia bautismal, desafiada por los nuevos escenarios políticos, sociales, culturales y económicos que circundan la vida cristiana.

\subsection{Los Ejercicios Espirituales como experiencia de encuentro con Jesucristo}

Es preciso adentrarse en el sentido y la finalidad de los ejercicios espirituales dentro de la experiencia cristiana, que, si bien toma elementos de la filosofía antigua, también ofrece una novedad en la forma como se comprenden y se viven, así como en la finalidad que pretenden alcanzar. De modo que "hay que entender los ejercicios espirituales como una experiencia fuerte de encuentro personal con Jesucristo; como una experiencia vigorosa de Dios; como una auténtica vivencia espiritual; como un momento fuerte de revitalización de la propia identidad cristiana" (Severino, 1984, p. 153).

Los ejercicios espirituales cristianos quieren ser una experiencia vital de encuentro con Jesucristo, para desde ella transformar la propia vida en un ambiente profundo de fe, silencio, oración y ascesis, que permita la libre actuación y captación, por parte de los ejercitantes, de las mociones del espíritu. La mencionada práctica cristiana pretende formar seres humanos y apóstoles del Señor, como bien lo precisa la carta encíclica "Mens Nostra": "Los Ejercicios espirituales tienen un maravilloso poder, así para perfeccionar las facultades naturales del individuo como principalmente para formar al hombre sobrenatural o cristiano" (Pío XI, 1929, p. 4).

Vivir a plenitud el Evangelio solo es posible gracias a la constante ejercitación en el espíritu, el cual exige de espacios de retiro del ruido, del activismo y de las preocupaciones para procurar discernir la voluntad divina. En este sentido, los ejercicios espirituales se comprenden como: 
Una fuerte experiencia de Dios, suscitada por la escucha de su Palabra, comprendida y acogida en la propia vida, bajo la acción del Espíritu Santo, la cual, en un clima de silencio, de oración y con la mediación de un guía espiritual, capacita para el discernimiento en orden a la purificación del corazón, a la conversión de vida y al seguimiento de Cristo, para el cumplimiento de la propia misión en la Iglesia y en el mundo. (Benedicto XVI, 2008, p. 2)

Sin embargo, no se conoce, ni se tiene experiencia de Dios por proselitismo, a través de conferencias ni de periodos largos de silencio, sino mediante el insondable misterio del Espíritu Santo, quien actúa donde quiere y cuando quiere, sin supeditar su obra a leyes ni formulaciones humanas, por ello, realizar ejercicios espirituales significará estar permanentemente dispuestos y atentos a escuchar y dejarse llevar por la voz del espíritu que hace siempre nuevas todas las cosas, por lo tanto, "quien vive los ejercicios de modo auténtico experimenta la atracción, la fascinación de Dios, y vuelve renovado, transfigurado a la vida ordinaria, al ministerio, a las relaciones cotidianas, llevando consigo el perfume de Cristo" (Francisco, 2014).

Los ejercicios espirituales se entienden como el "modo de examinar la conciencia, de meditar de contemplar, de orar vocal y mental, y de otras espirituales operaciones" (De Loyola, 2013, p. 9), con el propósito firme de "quitar de sí todas las afecciones desordenadas y, después de quitadas, para buscar y hallar la voluntad divina" (Loyola, 2013, p. 9).

Los ejercicios espirituales son un camino "para vencerse a sí mismo y ordenar su vida, sin determinarse por afección alguna que desordenada sea" (De Loyola, 2013, p. 17); de esta manera, la tarea propia del ejercitante está en tomar conciencia de aquellas afecciones que lo apartan del fin más íntimo anhelado por su alma desde la creación. Se trata de ordenar la propia vida: los pensamientos, sentimientos, deseos, inteligencia, voluntad humana, corazón, en pocas palabras, de ser capaz de disponer el corazón para hacer la voluntad divina, siguiendo un camino interior de conversión que se puede considerar en tres momentos: 1) hacia adentro - consigo mismo - revisando la propia vida, quién se es; 2) salir hacia los otros, viviendo las relaciones interpersonales de una forma diferente; y 3) leyendo el mundo y la realidad que permite contemplar la creación, marcados por la experiencia de concebir a Dios de una manera diferente. 


\subsection{Etapas del camino de discernimiento vocacional desde los ejercicios espirituales}

La vida es un camino, en consecuencia, es un proceso dinámico que exige ir ahondando, cada vez más y de forma gradual, en las mociones del Espíritu Santo. Recorrer el sendero de la fe exige hondura espiritual, y esta no se alcanza de un día para otro; por ello se proponen tres etapas fundamentales en el proceso de discernimiento vocacional: 1) catecumenal; 2) discipular; y 3) configuración.

\subsubsection{Etapa catecumenal}

El proceso de catecumenado ha sido una práctica de la Iglesia desde sus orígenes mismos, para responder a la misión evangelizadora de los pueblos. Por ello, el Concilio Vaticano II sugiere: "restáurese el catecumenado de adultos, dividido en distintas etapas y grados, cuya práctica dependerá del juicio del ordinario del lugar" (SC, n. 64). Ello, con el ánimo no solo de preparar a quienes lo desean para el sacramento del bautismo, sino, además, de ser un instrumento de crecimiento en la fe para quienes se han bautizado, pero viven alejados de esta.

La etapa catecumenal aquí sugerida, "será útil para cuantos quieran ahondar en su vida cristiana, bien individualmente o por medio de reuniones periódicas en las que, a modo de neocatecumenados, se replantean los compromisos de su fe y de su bautismo" (Comisión Episcopal de Liturgia, 1990, p. 5) y conduzcan, de esta forma, a procesos serios de discernimiento vocacional.

En el contexto actual, no se puede suponer que todos los jóvenes son cristianos, se requiere un proceso de clarificación acerca de las motivaciones de fe, mayor profundidad catequética y un proceso de purificación de todo aquello que impide optar por el proyecto del Reino. Es necesario ahondar en el conocimiento de Cristo y las exigencias del Evangelio para quien desea seguirlo. Solo quien se encuentra y conoce al Señor puede transformar su vida. Por lo cual, se plantea iniciar esta experiencia desde grado noveno, que corresponde a edades entre los 14 y los 15 años, aproximadamente, en las cuales muchos jóvenes están preparándose para realizar el sacramento de la confirmación, además, es una edad suficiente para forjar convicciones y realizar cambios significativos en la propia vida. Se propone la catequesis sistemática y profunda que comienza con el primer encuentro vocacional al cual asiste el joven, la cual será profundizada a través de un seguimiento mensual por parte de quien acompaña el proceso de conocimiento de la persona del Señor Jesucristo y de maduración en la vida de fe. 
Como momento de cierre de esta primera etapa se espera un proceso de conversión a la persona de Jesús y su proyecto, para esto es necesario crecer en la conciencia suficiente de la situación personal, a partir de dos preguntas fundamentales, las cuales evidencian la relación consigo mismo: 1) ¿quién soy yo?, pregunta clave por la identidad. Para ello se debe partir de la relectura de la historia personal de vida (mi historia y lo que he hecho con ella, sentimientos, deseos); y 2) ¿qué busco en la vida?, es decir, ¿a dónde se orienta mi corazón? Lo que permitirá fijarse metas a través de un proyecto de vida que se establece a partir de las orientaciones y mociones del espíritu en la vida del creyente. Los instrumentos de acompañamiento para esta etapa son la elaboración de la propia autobiografía y la construcción del proyecto personal de vida; todo esto iluminado bajo el conocimiento de Cristo, lo que permite analizar opciones maduras de vida, y proyectar la hoja de ruta en la vida de fe.

Esta etapa catecumenal "requiere ante todo la propia conversión, madurada progresivamente, [...] ha de ser adaptada al punto del itinerario espiritual en que se encuentran los candidatos, o sea, a su progreso en la fe y a la formación catequética que reciben" (Comisión Episcopal de Liturgia, 1990, p. 119), dicho proceso debe estar cimentado en el conocimiento de la persona de Jesús y de sí mismo. De tal modo que, a la vez que permite confrontarse con la propuesta evangélica, el joven va dando pasos en la elaboración de su proyecto de vida personal, el cual le permitirá hacer un camino de conversión alentado por convicciones de fe.

\subsubsection{Etapa discipular}

El seguimiento de la persona de Cristo es la consecuencia directa del encuentro con Él. “De hecho, Jesús no solo fascinó con su vida, sino que también llamó explícitamente a la fe. [...] otros que lo conocieron fueron llamados a convertirse en sus discípulos y testigos" (Secretaría General del Sínodo, 2018, p. 22), en consecuencia, solo Jesús tiene el poder de transformar el corazón y de renovar la existencia, de ahí que este momento corresponde a un tiempo de seguimiento de la persona del Señor Jesús y al progreso en la vida espiritual del dirigido. Por ello, se debe precisar la singularidad de cada persona, puesto que cada uno hace un camino diferente, que no obedece a tiempos ni estándares preestablecidos, sino al camino de fe realizado según ritmos y tiempos. "Jesús nos invita a encontrarnos con Él y a que nos vinculemos estrechamente con Él, porque es la fuente de la vida (Jn 15, 5-15) y solo Él tiene palabras de vida eterna (Jn 6, 68)" (Celam,

\section{Universidad Santo Tomás, Facultad de Teología}


2005, p. 72) sin Él no se puede hacer nada en la vida y mucho menos pretender la eternidad bienaventurada.

El Evangelio es contundente frente a la naturaleza del seguimiento: "Jesús los eligió para 'que estuvieran con Él y enviarlos a predicar' (Mc 3, 14), para que lo siguieran con la finalidad de 'ser de Él' y formar parte 'de los suyos' y participar de su misión" (Celam, 2005, p. 72). Ser de Cristo y anunciarlo al mundo es el objeto mismo del discipulado, el cual dinamiza la fe y, a la vez, da sentido al estilo propio propuesto por el Maestro. Esta etapa busca que el joven realice una elección de vida seria y madura, la cual le permitirá evaluar la opción de vida. Será el momento preciso para valorar la relación con Dios (vida de fe, ejercitación en la oración, inserción eclesial, la vida interior, la práctica de las virtudes cristianas y la vivencia de los consejos evangélicos, configuración con Cristo...).

Esta etapa se propone para jóvenes de décimo grado, en edades entre 15 y 16 años. En ella, se debe intensificar el proceso catequético que afiance los rasgos propios del discípulo para que tenga "como centro la persona de Jesucristo, nuestro salvador y plenitud de nuestra humanidad, fuente de toda madurez humana y cristiana; que tenga espíritu de oración, sea amante de la Palabra, practique la confesión frecuente y participe de la eucaristía" (Celam, 2005, p. 139), y que todo ello se refleje en prácticas concretas de vida cristina, para que como discípulo "se inserte cordialmente en la comunidad eclesial y social, sea solidario en el amor y fervoroso misionero (Celam, 2005, p. 139).

Este segundo momento exige capacidad de reorganización racional de la propia vida con respecto a la propuesta evangélica, lo que implica responder: 1 ) ¿hacia dónde voy? En este momento determinado de mi vida ¿cuál es mi realidad? - es el momento para prestar atención a los sentimientos, emociones, las cuales ocupan mi mente y las acciones propias del momento histórico particular de mi vida-; 2) ¿dónde estoy según el deseo de mi corazón?, es decir, en qué parte del camino me encuentro con respecto a la elección de vida realizada con antelación - es el espacio oportuno para confrontar lo que se es con aquello elegido y las exigencias por haber escogido esa opción-.

Los instrumentos de acompañamiento propuestos para este camino son la confesión, el coloquio constante con el director espiritual y los escrutinios de vida, los cuales permiten constatar la disponibilidad del discípulo para seguir al Señor. 


\subsubsection{Etapa de configuración}

Luego de un proceso de conversión inicial, y de la experiencia de discipulado como opción de vida cristiana, le corresponde al discípulo hacer camino con el Maestro, en el que guiado y acompañado por Él haga propios los sentimientos de Cristo (Fl 2,5) en su vida. “El discípulo experimenta que la vinculación íntima con Jesús en el grupo de los suyos es participación en la Vida salida de las entrañas del Padre, es formarse para asumir su mismo estilo de vida y sus mismas motivaciones" (Celam, 2005, p. 72), para, de esta manera, "correr su misma suerte y hacerse cargo de su misión de hacer nuevas todas las cosas" (Celam, 2005, p. 72).

La experiencia cristiana no puede dejar al discípulo indiferente ante la propuesta del Reino, por ello, es el momento de reafirmar las opciones de vida y de poner por obra aquello en lo que se cree y da sentido a la existencia. Esta etapa se propone para los jóvenes entre 17 y 18 años que están en grado once. Este tercer tiempo de perfección exige un cambio de comportamiento en la persona. Se trata de confirmar la elección realizada, no solo de palabra sino con las obras, pues, como ya se ha optado por Jesús y su proyecto, ahora se debe elegir el estilo particular de seguimiento desde el cual se quiere vivir la fe cristiana.

La pregunta fundamental para este momento es: Ante esto ¿qué tengo que hacer? Para responder al querer de Dios en la propia vida se deben revisar las cosas y las actitudes que habrán de quedar atrás para seguir el proyecto de Jesús. Es el momento para ver la relación con los demás (familia, trabajo, estudio, amistades, apostolado...) y el lugar de estos en la opción de vida a través de la respuesta dada. Como instrumento de acompañamiento en esta etapa se propone una experiencia fuerte de misión y de servicio a los demás, a través de un apostolado concreto o una experiencia de voluntariado, como expresión firme de la vivencia de la caridad cristiana manifestada en el servicio a los demás.

Estas tres etapas pretenden ser un itinerario posibilitador de acompañamiento espiritual, acorde a los desafíos pastorales del contexto actual. Ante esta realidad, el acompañamiento espiritual está mediado por la experiencia profunda de fe en la cual "para el creyente, la vida no es un hecho del azar, y mucho menos empeño del querer humano: Toda vida es voluntad de Dios, en su proyecto salvífico, Dios asigna un lugar, una tarea a cada vida humana" (Chávez, 2013, p. 26), por ello, el ser humano debe estar siempre atento a descubrir y vivir el proyecto de santidad pensado por Dios en la propia vida cristiana. 


\section{Conclusiones}

Asistimos a un momento de la historia caracterizado por cambios en todos los estamentos de la vida social y el relativismo en la escala de valores políticos, religiosos, culturales, entre otros, ante los cuales no es fácil hacer opciones vocacionales claras y mantenerse firme ante ellas en un contexto sociocultural como el de la última época. Los tiempos cambian y junto con ellos aparecen cada día nuevos retos para la humanidad y aún más para la vida de la Iglesia. Ante estas realidades existenciales, los jóvenes necesitan ser acompañados y se hace indispensable que la Iglesia se haga compañera de camino de tantos hombres y mujeres sedientos de esperanza, para animarlos a la vivencia de los valores evangélicos menos acogidos en determinados contextos de hoy.

El sínodo sobre los jóvenes nos recuerda que ellos "están llamados a tomar decisiones que guíen su existencia; expresar el deseo de ser escuchados, reconocidos, acompañados. Muchos experimentan cómo su voz no se considera interesante y útil en el campo social y eclesial" (Secretaría General del Sínodo, 2018, p. 4). Por tanto, el contexto actual exige una mayor atención pastoral a los jóvenes dentro de la vida eclesial, a lo cual, se ha respondido desde diferentes espacios.

El objetivo del acompañamiento espiritual es ayudar a la persona a ser más fiel a su condición cristiana, mediante el seguimiento de Jesucristo en una vocación particular, la cual debe ser discernida a la luz de la fe y el acompañamiento vocacional, para esto, los ejercicios espirituales - desde la dimensión humanason un medio para aprender a vivir y morir. Esta realidad descubre el carácter transformativo de los mismos, valiéndose del examen de conciencia para liberar las pasiones y los deseos del individuo no acordes con su estado de vida, y le permiten la concentración y unificación del alma mediante un camino formativo interior, que implica a la totalidad del individuo, impulsándolo a vivir y morir con coherencia según la propia elección de vida.

Los ejercicios espirituales cristianos quieren ser una experiencia vital de encuentro con Jesucristo, para desde ella transformar la propia vida en un ambiente profundo de fe, silencio, oración y ascesis, que permita la libre actuación e ineriorización por parte de los ejercitantes de las mociones del Espíritu. Esta práctica eclesial pretende ser un encuentro existencial con Jesucristo que busca revitalizar la identidad cristiana mediante el discernimiento vocacional suscitado por la acción vivificante del Espíritu Santo en cada creyente, iluminado por la Palabra de Dios y las diferentes mediaciones divinas, formando así seres humanos y discípulos del Señor. 
El acompañamiento vocacional planteado es posible gracias a tres etapas que se han propuesto para el desarrollo de los ejercicios espirituales: 1) etapa catecumenal, que favorece mediante la catequesis continua un proceso de conversión de la vida como fruto del encuentro con la persona de Cristo; 2) etapa del discipulado, que ayuda a revisar la fidelidad a la opción realizada en orden al seguimiento de Cristo; y 3) etapa de configuración, que tiene por objetivo ayudar al discípulo a apropiar los valores del Reino propuestos por Jesús, para lo cual se proponen los ejercicios como instrumento continuo de clarificación y revisión constante de la vivencia de la identidad cristiana por parte de quien se ejercita en la vida del Espíritu.

Cada día se constata la urgencia pastoral de saber acompañar en el camino de fe ante la proliferación de religiones, filosofías y demás propuestas del mundo contemporáneo que, en lugar de ayudar a los jóvenes a centrarse en torno a un proyecto de vida claro, ofrecen un mayor sin sentido de vida a no pocas personas, que están marcadas por la cultura de lo mediático, del relativismo y lo cambiante de los modelos y parámetros sociales que hacen que 'todo valga', que cualquier opinión sea una verdad, y que cualquier manera de ser y de vivir se convierta en modelo de referencia para muchos, una fuente de felicidad y realización que al cabo de un tiempo demuestra ser una promesa vacía y carente de sentido para otros.

El acompañamiento espiritual en el camino vocacional es una necesidad de todo bautizado; de una manera particular, los ejercicios espirituales son un punto de apoyo para descansar y retomar, con mayores energías, el proceso de seguimiento que muchas veces se debilita por las dificultades y los tropiezos propios de la vida cristiana. Es un espacio propicio para revisar la opción de vida y reconfigurar el corazón con la Palabra, fuente verdadera de vida y felicidad.

\section{Referencias}

Baena, G. (2003). Fundamentos del discernimiento en la revelación: ¿cómo acoge el ser humano la voluntad de Dios? Apuntes Ignacianos, 37.

Benedicto XVI. (2006). Carta encíclica Deus Caritas Est. Librerías Paulinas.

Benedicto XVI. (2008). Discurso a la XXIII asamblea general de la federación italiana de ejercicios espirituales. La Santa Sede. http://www.vatican.va/content/benedict-xvi/ es/speeches/2008/february/documents/hf_ben-xvi_spe_20080209_fies.html

Blondel, M. (1996). La Acción (1983). Ensayo de una crítica de la vida y de una ciencia de la práctica. Biblioteca de Autores Cristianos. 
Cebollada, P. (2017). El acompañamiento espiritual en la historia. Revista CONFER, 56(214), 293-313.

Chávez, P. (2013). Formación y vocación: don y compromiso. Salesianos Don Bosco. https://www.sdb.org/es/RM_Recursos/ACG_Lettere/Don_Chavez/Vocacion_y_ Formacion

Comisión Episcopal Española de Liturgia. (1990). Ritual de la iniciación cristiana de adultos. Conferencia Episcopal Española. https://www.obispadoalcala.org/pdfs/ RICA.pdf

Concilio Vaticano II. (1965). Constitución Sacrosantum Concilium sobre la sagrada liturgia. La Santa Sede. http://www.vatican.va/archive/hist_councils/ii_vatican_ council/documents/vat-ii_const_19631204_sacrosanctum-concilium_sp.html

Concilio Vaticano II. (1965a). Decreto Presbyterorum Ordinis sobre el ministerio y vida de los presbíteros. La Santa Sede. http://www.vatican.va/archive/hist_councils/ ii_vatican_council/documents/vat-ii_decree_19651207_presbyterorum-ordinis_ sp.html

Concilio Vaticano II. (1965b). Constitución Pastoral Gaudium et Spes sobre la iglesia en el mundo de hoy. La Santa Sede.

Congregación para el Clero. (2011). El sacerdote confesor y director espiritual ministro de la misericordia divina. Librería Editrice Vaticana.

Consejo Episcopal Latinoamericano (Celam). (2005). V Conferencia General del episcopado Latinoamericano y del Caribe. Celam. https://www.celam.org/aparecida/Espanol.pdf

De Loyola, I. (1983). El Peregrino Autobiografía. Mensajero Ediciones.

De Loyola, I. (2013). Ejercicios Espirituales. Sal Terrae.

Francisco. (2013). Exhortación Apostólica "Evangelii Gaudium". La Santa Sede. https:// w2.vatican.va/content/dam/francesco/pdf/apost_exhortations/documents/ papa-francesco_esortazione-ap_20131124_evangelii-gaudium_sp.pdf

Francisco. (2014). Discurso a los participantes en la Asamblea de la Federación Italiana de Ejercicios Espirituales. La Santa Sede. http://www.vatican.va/content/francesco/ es/speeches/2014/march/documents/papa-francesco_20140303_federaz-esercizispirituali.html

Franco, M. (2004). Perspectivas Bíblicas del acompañamiento espiritual. Apuntes ignacianos, 40, 10-36.

Frankl, V. (2003). Ante el vacío existencial. Hacia una humanización de la psicoterapia. Herder Editorial.

García, L. (2017). Qué es y qué no es acompañamiento espiritual. Sal terrae: Revista de teología pastoral, 105(1227), 865-877. 
García, S. (2001). El acompañamiento. Un ministerio de ayuda. Editorial Paulinas.

Giner, S., Lamo, E. y Torres, C. (1998). Diccionario de Sociología. Alianza Editorial.

Heinz, K. (2005). Diccionario enciclopédico de Sociología. Herder Editorial.

Kant, I. (2003). Lógica. Biblioteca Virtual Universal. https://biblioteca.org.ar/libros/89474. pdf

Lasso, M. (2011). Fuera de lo humano no hay salvación. Proceso de humanización y de espiritualidad cristiana [Tesis de pregrado, Pontificia Universidad Javeriana].

Melloni, X. (1998). Los Ejercicios en la tradición de Occidente. Cometa.

Mifsud, T. (2002). Una fe comprometida con la vida. https://mercaba.org/ARTICULOS/U/ una_fe_comprometida_con_la_vida.htm

Oraá, A. (1954). Ejercicios espirituales de San Ignacio de Loyola: explanación de las meditaciones y documentos en ellos contenidos. Razón y Fe.

Pablo VI. (1975). Exhortación apostólica de su santidad Pablo VI “Evangelii Nuntiandi". La Santa Sede. http://www.vatican.va/content/paul-vi/es/apost_exhortations/documents/hf_p-vi_exh_19751208_evangelii-nuntiandi.html

Pio XI. (1929). Carta encíclica "Mens Nostra" sobre los ejercicios espirituales. La Santa Sede. http://www.vatican.va/content/pius-xi/es/encyclicals/documents/hf_ p-xi_enc_19291220_mens-nostra.html

Raczkiewicz, M. (2010). La escandalosa vida de los cristianos. Moralia: revista de ciencias morales, 133(33), 27-54.

Rahner, K. (1976). Oyente de la Palabra. Fundamento para una filosofía de la religión. Herder Editorial.

Roldán, A. (2004). La Iglesia frente al desafío de la posmodernidad y el pluralismo. Teología y Cultura, 1(1), 3-19.

Ruiz, E. (2015). La pedagogía salesiana: un espacio posibilitador de humanismo cristiano [Tesis de pregrado, Pontificia Universidad Javeriana].

Secretaría General del Sínodo. (2018). Documento final y votos del Documento final del Sínodo de los Obispos al Santo Padre Francisco. http://celam.org/Images/img_noticias/ doc35bd8607dab689_30102018_745am.pdf

Severino, M. (1984). Proyecto personal de vida espiritual. Ejercicios espirituales o ejercitación en el espíritu. Publicaciones Claretianas.

Tertuliano, Q. (1789). Apología contra los gentiles. Oficina de D. Benito Cano.

Torralba, F. (1998). Poética de la libertad. Lectura de Kierkegaard. Caparrós Editores. 


\section{Bibliografía consultada}

Ruiz, E. (2017). (Apuntes clases de maestría). Universidad Pontificia Bolivariana.

Torralba, F. (2010). Inteligencia espiritual. Plataforma Editorial. 